\title{
NEONATAL THROMBOCYTOPENIC PURPURA IN TWO INFANTS
}

\author{
BY \\ M. L. NEVILLE and L. M. MASTERMAN \\ From Selly Oak Hospital, Birmingham
}

(RECEIVED FOR PUBLICATION NOVEMBER 19, 1953)

Cases of purpura in the newborn have been recorded fairly frequently, and Robson and Walker (1951) have recently reviewed the literature of some 52 cases. Three types of congenital purpura are recognized: (1) Purpura when the mother is affected; (2) purpura when the mother is normal; (3) purpura associated with hypoplasia of the bone marrow.

The essential characteristics in the diagnosis of idiopathic thrombocytopenic purpura in the adult are: (1) A platelet count of 100,000 or less; (2) no other cause for purpura; (3) normal clotting time; (4) prolonged bleeding time; (5) bone marrow normal or showing increased megakarocytes. The same criteria may be applied to neonatal cases. The literature shows over 30 such cases of congenital thrombocytopenic purpura occurring in the newborn in which the mother had the same disease, and amongst these McAlenney and Kristan (1949) found nine instances in which splenectomy had been performed on the mother.

In the following account the mother had idiopathic thrombocytopenic purpura in 1938 when she was 15 years old, and both her infants, born in 1950 and in 1952, showed neonatal purpura.

\section{Case Report}

I.M. was born in 1922. She first attended Selly Oak Hospital in 1938 when she was admitted with severe menorrhagia; her condition was diagnosed as thrombocytopenic purpura, and after transfusion the spleen was removed.

She next attended the Out-Patient Department in 1948 when she contemplated marriage, and wished to know if pregnancy was contraindicated. In the intervening 10 years her health had been good, but she continued to bruise easily and her periods, which lasted four days, were rather heavy.

On examination she showed a few ecchymoses on arms, legs and chest. The capillary resistance test of Hess was positive.

The bleeding time was 10 minutes and the clotting time $3 \frac{1}{2}$ minutes. A blood count gave $\mathrm{Hb} 11.7 \mathrm{~g}$. \%;
R.B.C.s, 4,000,000; leucocytes, 6,400; platelets, 47,000; and reticulocytes less than $1 \%$. The blood was $R h$ positive, the erythrocyte sedimentation rate was $3 \mathrm{~mm}$. in one hour and clot retraction was normal.

She was advised to attend hospital for antenatal care and delivery should she become pregnant.

On March 14, 1950, she reported at the ante-natal clinic. She was 12 weeks pregnant. Her general health was good, and a blood count showed: $\mathrm{Hb}, 13 \mathrm{~g} . \%$; R.B.C.s, 4,700,000; platelets, 56,000; clotting time, $3 \frac{1}{2}$ minutes and bleeding time, $2 \frac{1}{2}$ minutes.

She attended regularly and remained well. On September 20 she was admitted in labour, which proceeded normally until after the birth of the placenta, when she rapidly lost 30 ounces of blood; one and a half hours later she again had a brisk loss of 12 ounces.

On September 22 a blood count gave $\mathrm{Hb}, 9 \cdot 1$ g. $\%$; R.B.C.s, 3,030,000; M.C.H., 30; leucocytes, 16,700; platelets, 27,200; clotting time, 3 minutes; bleeding time $4 \frac{1}{2}$ minutes; prothrombin time, 21 seconds; and prothrombin consumption poor.

FURTHER BLOOD COUNTS OF D.M.

\begin{tabular}{|c|c|c|c|}
\hline Date & $\mathrm{Hb}(\mathrm{g} . \%)$ & R.B.C.s & Platelets \\
\hline 16.10 .50 & $8 \cdot 8$ & $2,670,000$ & Less than 10,000 . \\
\hline $\begin{array}{r}19.10 .50 \\
2.11 .50 \\
8.11 .50 \\
11.11 .50 \\
23.11 .50 \\
21.12 .50 \\
15.2 .51 \\
12.4 .51 \\
5.7 .51 \\
25.7 .51 \\
4.9 .52\end{array}$ & $\begin{array}{r}8 \cdot 7 \\
8 \cdot 0 \\
7 \cdot 4 \\
13 \cdot 0 \\
10 \cdot 6 \\
11.4 \\
11 \cdot 6 \\
12 \cdot 3 \\
11.9 \\
11.0 \\
11 \cdot 4\end{array}$ & $\begin{array}{l}2,670,000 \\
2,560,000 \\
2,300,000 \\
4,300,000 \\
3,930,000 \\
3,900,000 \\
4,370,000 \\
4,090,000 \\
3,410,000 \\
3,400,000 \\
3,340,000\end{array}$ & $\begin{array}{l}66,000 \\
56,000 \\
46,000 \text {. Blood transfusion } \\
78,000 \\
94,000 \\
131,000 \\
244,500 \\
341,000 \\
340,000 \\
220,400\end{array}$ \\
\hline
\end{tabular}

The puerperium was normal. There was no further bleeding.

D.M., a boy, was born on September 20 (birth weight $8 \mathrm{lb} .13 \mathrm{oz}$.). A petechial rash was noticed at birth.

Bruising on both scapulae and on the arms was noted on September 27. A petechial rash was seen on the scalp, buttocks, back and limbs; the heels were bruised. The general condition was good, and the spleen was not felt.

A blood count on September 22 gave: $\mathrm{Hb}, 14 \cdot 8 \mathrm{~g}$. \%; R.B.C.s, 4,200,000; M.C.H., $35 \mathrm{~mm}$.; platelets, 50,500; 
clotting time, 3 minutes and bleeding time, 6 minutes. On that day the scrotum and heels were discoloured, but the petechial rash had almost disappeared. Three days later the petechiae and bruising were fading, there was no haemorrhage. Meconium was normal. On September 27 haemoglobin was $12 \cdot 8 \mathrm{~g}$. \% and platelets 10,000 .

After the initial post-natal phase the child's progress has been very good. No further petechiae or abnormal bruising have occurred, and he remains quite normal.

In January, 1952, I.M. again attended the ante-natal department. Her health was good, but a few petechial spots were seen on the legs.

\section{BLOOD COUNTS DURING SECOND PREGNANCY}

\begin{tabular}{c|c|c|c}
\hline & & & \\
Date & Hb (8.\%) & R.B.C.s & Platelets \\
\hline 20.3.52 & $12 \cdot 7$ & $4,670,000$ & 140,000 \\
17.4 .52 & $13 \cdot 0$ & $5,000,000$ & 74,000 \\
26.4 .52 & $15 \cdot 2$ & 121,000 \\
29.5 .52 & & $4,010,000$ & 314,000 \\
12.6 .52 & & 368,920 \\
\hline
\end{tabular}

On June 25,1952 , she was delivered normally of a full term girl (J.M.) weighing $7 \mathrm{lb} .13 \mathrm{oz}$.

There was no abnormal bleeding.

On June $2410 \mathrm{mg}$. of Vitamin $\mathrm{K}$ was given, and on June 25 a further $10 \mathrm{mg}$. A blood count on June 26 gave Hb, 15.2 g. \%; R.B.C.s, 5,080,000; M.C.H., 29.9; platelets, 121,920; clotting time, 3 minutes 45 seconds and bleeding time 2 minutes.

The puerperium was uneventful, and the patient and her baby went home on the tenth day. Since then I.M. has been seen frequently, and has had normal blood counts and a platelet count above 100,000.

No bruising or petechiae were seen at birth of J.M. at 5.30 a.m. but during the day petechial haemorrhage appeared on the scalp, buttocks and beneath the binder. On the next day the infant was very well, but the petechial haemorrhages persisted. She had no melaena, and passed normal meconium.

BLOOD COUNTS OF J.M.

\begin{tabular}{|c|c|c|c|}
\hline Date & $\mathrm{Hb}(\mathrm{g} . \%)$ & R.B.C.s & Platelets \\
\hline $\begin{array}{c}25.6 .52 \\
\text { Cord blood } \\
\text { Heel blood } \\
27.6 .52 \\
29.6 .52 \\
30.6 .52 \\
2.7 .52 \\
7.8 .52 \\
4.9 .52 \\
3.10 .52\end{array}$ & $\begin{array}{l}14 \cdot 6 \\
19 \cdot 6 \\
19 \cdot 6 \\
18.7 \\
19 \cdot 8 \\
18 \cdot 8 \\
13 \cdot 3 \\
10.6 \\
10.6\end{array}$ & $\begin{array}{l}3,870,000 \\
5,400,000 \\
5,820,000 \\
5,480,000 \\
5,800,000 \\
5,490,000 \\
3,680,000 \\
3,330,000 \\
3,560,000\end{array}$ & $\begin{array}{r}22,400 \\
34,920 \\
65,760 \\
29,400 \\
27,450 \\
22,000 \\
199,800 \\
270,000\end{array}$ \\
\hline
\end{tabular}

The infant's' progress was satisfactory with a steady gain in weight, and no recurrence of bruising or petechiae.

\section{Comment}

The mother, who was known to have had thrombocytopenic purpura at the age of 15 when her spleen was removed, still showed evidence of this disease 10 years later. She did not bleed severely and her general health was good. During the first pregnancy she had petechial rashes and there was a small post-partum haemorrhage after a normal delivery. The platelet count was low during pregnancy and after delivery. The male infant showed more bruising and rash than his sister. Although there was no intestinal or other haemorrhage, his haemoglobin dropped to $7.4 \mathrm{~g}$. $\%$, and his platelets remained below 72,000 until after the blood transfusion on November 8 at the age of 6 weeks. The progress since then has been entirely satisfactory with normal blood counts since the age of 3 months.

The female infant was less affected than her brother, and their mother was in very good health during this second pregnancy. Her haemoglobin, R.B.C.s and platelets were normal, and after delivery the platelets were 121,920 . Her daughter's blood counts remained satisfactory in spite of the low platelet count which rose to over 100,000 after 10 weeks of age. Since then she has been well, and her blood counts have all been normal.

The hereditary factor in this disease has been discussed by a number of writers:

Sanford, Leslie and Crane (1936) describes a case where the infant was born with purpura. The mother suffered from petechial haemorrhage, and had a low platelet count; her mother also had purpura. Morrison and Samwick (1945) record a similar case of grandmother, mother and infant.

In our family no further history of purpura could be elicited. There is no evidence of thrombocytopenic purpura in her mother.

Both children appear to be free from the disease at present, and it is impossible to say whether they have inherited the factor causing the disease, or whether this tendency passed through the placenta before delivery, giving rise to a temporary thrombocytopenia. The rapid subsidence of the purpura and thrombocytopenia after the establishment of independent life favours the second assumption, and only prolonged observation will show whether the disease remains latent in the two children.

\section{Summary}

Thrombocytopenic purpura occurring in two infants whose mother was known to have had the disease at the age of 15 , when splenectomy was done, is described.

\section{REFERENCES} McAlenney, P. F. and Kristan, J. J. (1949). Amer. J. Dis. Child., 78,

Morrison, M. and Samwick, A. A. (1945). Ibid., 70, 115.

Robson, H. N. and Walker, C. H. M. (1951). Archives of Disease in Childhood, 26, 175 .

Sanford, H. N., Leslie, E. I. and Crane, M. M. (1936). Amer. J. Dis. Child., 51, 1114 